\title{
Radiofrequency ablation combined with conductive fluid-based dopants (saline normal and colloidal gold): computer modeling and ex vivo experiments
}

\author{
Dora Luz Castro-López ${ }^{1}$, Enrique Berjano ${ }^{2}$ and Ricardo Romero-Mendez ${ }^{1 *}$ (1)
}

\author{
${ }^{*}$ Correspondence: \\ rromerom@uaslp.mx \\ 1 Facultad de Ingeniería, \\ Universidad Autónoma de \\ San Luis Potosí, San Luis \\ Potosí SLP 78290, México \\ Full list of author information \\ is available at the end of the \\ article
}

\begin{abstract}
Background: The volume of the coagulation zones created during radiofrequency ablation (RFA) is limited by the appearance of roll-off. Doping the tissue with conductive fluids, e.g., gold nanoparticles (AuNPs) could enlarge these zones by delaying roll-off. Our goal was to characterize the electrical conductivity of a substrate doped with AuNPs in a computer modeling study and ex vivo experiments to investigate their effect on coagulation zone volumes.

Methods: The electrical conductivity of substrates doped with normal saline or AuNPs was assessed experimentally on agar phantoms. The computer models, built and solved on COMSOL Multiphysics, consisted of a cylindrical domain mimicking liver tissue and a spherical domain mimicking a doped zone with 2, 3 and $4 \mathrm{~cm}$ diameters. Ex vivo experiments were conducted on bovine liver fragments under three different conditions: non-doped tissue (ND Group), $2 \mathrm{~mL}$ of $0.9 \% \mathrm{NaCl}$ ( $\mathrm{NaCl}$ Group), and $2 \mathrm{~mL}$ of AuNPs 0.1 wt\% (AuNPs Group).
\end{abstract}

Results: The theoretical analysis showed that adding normal saline or colloidal gold in concentrations lower than $10 \%$ only modifies the electrical conductivity of the doped substrate with practically no change in the thermal characteristics. The computer results showed a relationship between doped zone size and electrode length regarding the created coagulation zone. There was good agreement between the ex vivo and computational results in terms of transverse diameter of the coagulation zone.

Conclusions: Both the computer and ex vivo experiments showed that doping with AuNPs can enlarge the coagulation zone, especially the transverse diameter and hence enhance sphericity.

Keywords: Gold nanoparticles, Nanofluid, Saline solution, Radiofrequency ablation

\section{Background}

Radiofrequency (RF) ablation (RFA) is a minimally invasive procedure used to thermally destroy tumors [1]. During the procedure a needle-like ablation electrode is inserted into the tumor and electrical current $(\sim 500 \mathrm{kHz})$ is conducted between this electrode

(C) The Author(s) 2021. This article is licensed under a Creative Commons Attribution 4.0 International License, which permits use, sharing, adaptation, distribution and reproduction in any medium or format, as long as you give appropriate credit to the original author(s) and the source, provide a link to the Creative Commons licence, and indicate if changes were made. The images or other third party material in this article are included in the article's Creative Commons licence, unless indicated otherwise in a credit line to the material. If material is not included in the article's Creative Commons licence and your intended use is not permitted by statutory regulation or exceeds the permitted use, you will need to obtain permission directly from the copyright holder. To view a copy of this licence, visit http://creativecommons.org/ licenses/by/4.0/. The Creative Commons Public Domain Dedication waiver (http://creativecommons.org/publicdomain/zero/1.0/) applies to the data made available in this article, unless otherwise stated in a credit line to the data. 
and a large-surface dispersive electrode placed on the patient's skin [2]. The electrical power is converted into heat by the Joule effect and causes cell death by coagulative necrosis when tissue temperature exceeds $50{ }^{\circ} \mathrm{C}$ for several minutes [3]. The thermally damaged tissue is known as the coagulation zone [4]. The therapeutic goal is to achieve a coagulation zone that covers the entire tumor. Unfortunately, the coagulation zone size is strongly limited by the appearance of a phenomenon called roll-off, which consists of the cessation of RF power due to a sudden increase in electrical impedance when the active electrode is completely surrounded by desiccated tissue (i.e., at $\sim 100{ }^{\circ} \mathrm{C}$ ) [5].

Larger coagulation zones could possibly be achieved by delaying roll-off as long as possible. Past studies have suggested injecting conductive fluids (such as saline solutions) into the target site before and/or during RFA [6-8]. The idea behind this 'fluid-modulated RFA' is to increase the electrical conductivity of the fluid-doped tissue and hence increase the deposited RF power in the target site. In theory, there is a direct relationship between saline concentration in the doped sample and its electrical conductivity $\sigma$ [9]. In practical terms, the higher $\sigma$ can delay the appearance of the first roll-off [10], which is crucial, since the coagulation zone volume is not greatly affected by power reapplications after this event [11] and increasing the saline infusion volume does not always lead to larger coagulation zones [12].

Since better results can be obtained by increasing dopant conductivity [8], nanofluid (NF), i.e., a fluid based on metallic nanoparticles (NPs) appears to be a suitable option. Most of the studies that combined NPs and RFA were not in the context of invasive RFA (where an electrode is inserted into the tumor), but rather in noninvasive RF-induced localized hyperthermia, in which the tumor is doped with NPs and RF fields are externally generated $[13,14]$. In fact, very few studies that combine NPs with invasive RFA have been published [15-18]. Merkle et al.[15] studied the effect of doping the medium with superparamagnetic iron oxide prior to RFA in agar phantoms and in vivo liver models and found no significant differences in terms of coagulation zone size in the in vivo model, possibly because the NF containing iron oxide was administered intravenously, which did not ensure effective doping of the target area. In contrast, Pedro et al. [16] did find larger coagulation zones when RFA was combined with intravenous administration of colloidal gold NF in an in vivo model (VX2 tumor in kidney). Wu et al. [17] studied the effect of injecting carbon-coated iron NF during RFA in an ex vivo model and found that this resulted in larger coagulation zones than those obtained by injecting saline only. In this case, the NF was injected directly through the electrode to ensure the doping of the target area. Likewise, Jelbuldina et al. [18] studied the effect of injecting NF based on ferromagnetic particles prior to RFA in an ex vivo liver model and reported significantly larger coagulation zone sizes.

Although these experimental results seem promising so far, there is still little information on the effect of NF injection prior to RFA on the size of the coagulation zone and its comparative advantage over saline injection. To fill this gap, we conducted a study with two objectives: (1) to characterize the changes in electrical conductivity of a substrate doped with either $0.9 \% \mathrm{NaCl}$ (normal saline) or $0.01 \mathrm{wt} \%$ colloidal gold (colloidal suspension of gold NPs-AuNPs in deionized water), and (2) to carry out a computer modeling study and ex vivo experiments on the effect of both dopants on the coagulation zone volumes created during RFA. While the numerical model provided information on the effect of RFA 
on different dopant concentrations and doped zone size, the ex vivo experiments were performed with a reduced set of parameters to verify the conclusions of the simulations. The results of this investigation revealed the advantages of using fluid-based dopants to produce larger tissue coagulation zones by delaying the first roll-off and suggest the appropriate tumor size and applied voltage conditions under which these effects can be produced.

\section{Results}

\section{Electrical characterization of doped phantoms}

Table 1 shows the results of the impedance and electrical conductivities measured in the agar phantom samples. As expected, the single agar samples had the lowest conductivity, which increased after doping the sphere with $\mathrm{NaCl}$ or AuNPs solution. The highest conductivity was obtained for $1.5 \mathrm{wt} \%$ of $\mathrm{NaCl}$ solution $(0.145 \mathrm{~S} / \mathrm{m})$, followed by $1 \mathrm{wt} \%$ of AuNPs solution $(0.138 \mathrm{~S} / \mathrm{m})$ and $1.0 \mathrm{wt} \%$ of $\mathrm{NaCl}$ solution $(0.113 \mathrm{~S} / \mathrm{m})$. The Analysis of variance confirmed that significant differences in the $Z$ values between the groups. The increase in electrical conductivity of the substrate agar gel can be seen in the results in Table 1 . Bennett [9] experimentally found the following frequency-independent (up to $100 \mathrm{kHz}$ ) linear relation between $\mathrm{NaCl}$ concentration and electrical conductivity of agar phantoms doped with $\mathrm{NaCl}$ :

$$
\sigma(\mathrm{S} / \mathrm{m})=215 \times \frac{(\text { grams of } \mathrm{NaCl})}{(\text { solution volume }, \mathrm{mL})}+0.0529 .
$$

The residual value we found without $\mathrm{NaCl}(0.067 \mathrm{~S} / \mathrm{m})$ is more or less in agreement with the offset reported by Bennett [9] in Eq. (1) and is possibly associated with the insoluble component of the agar phantoms at room temperature since deionized water has extremely low electrical conductivity, $<0.2 \mathrm{mS} / \mathrm{m}$. When Eq. (1) was used to estimate the electrical conductivities in our cases of $\mathrm{NaCl}$ doping, we obtained smaller values than those found experimentally (e.g., $0.09 \mathrm{~S} / \mathrm{m}$ instead of $0.113 \mathrm{~S} / \mathrm{m}$ for $\mathrm{NaCl} 1 \mathrm{wt} \%$; and $0.1 \mathrm{~S} / \mathrm{m}$ instead of $0.145 \mathrm{~S} / \mathrm{m}$ for $\mathrm{NaCl} 1.5 \mathrm{wt} \%$ ). This disagreement could be due to the accumulated errors in the experimental measurement of $Z$ and the subsequent estimation of $\sigma$ by computer modeling. We thus proposed a similar equation to Eq. (1) that relates the electrical conductivity of a substrate doped with $0.01 \%$ AuNPs with its concentration in the substrate. Based on the experimental data obtained ( $1 \mathrm{wt} \%, 0.138 \mathrm{~S} / \mathrm{m})$ this would be:

$$
\sigma(\mathrm{S} / \mathrm{m})=0.071 \cdot(w t \%)+\sigma_{S},
$$

where $\sigma_{S}$ is the electrical conductivity of non-doped substrate. It should be emphasized that this expression is only approximate, since it is based on a single concentration value.

Table 1 Impedance measured from phantom samples $(n=10)$ and $\sigma$ values (estimated from computer simulations) of the agar-gel cylinder and of sphere

\begin{tabular}{llll}
\hline Phantom sample & $\boldsymbol{Z}(\boldsymbol{\Omega})$ & $\boldsymbol{\sigma}_{\text {agar-gel }}(\mathrm{S} / \mathrm{m})$ & $\boldsymbol{\sigma}_{\text {sphere }}$ (S/m) \\
\hline Agar & $322.4 \pm 2.7$ & 0.067 & 0.067 \\
Agar+ $\mathrm{NaCl}(1 \mathrm{wt} \%)$ & $213.6 \pm 2.4$ & 0.067 & 0.113 \\
Agar+ $\mathrm{NaCl}(1.5$ wt\%) & $177.5 \pm 4.1$ & 0.067 & 0.145 \\
Agar + AuNPs (1 wt\%) & $185.9 \pm 6.2$ & 0.067 & 0.138 \\
\hline
\end{tabular}


Theoretical estimates of the electrical conductivity of AuNPs colloidal solutions or substrates doped with this solution are difficult to calculate, since they depend on many factors, including the measurement frequency or NP size [19]. In this respect, expression (2) would be limited to a frequency of $500 \mathrm{kHz}$ and NPs size of $10 \mathrm{~nm}$.

\section{Computational results}

As the results showed that the doped zone has a crucial effect on the temperature distributions and the size of the coagulation zone, we give the results for each doped zone size separately. Table 2 shows the results for 50,70 and 90 V RFA until roll-off for the 2-cm doped zone, and Fig. 1 gives the related temperature distributions. As expected, initial impedance declined slightly as dopant concentration increased, with generally lower values in the case of AuNPs. Time to roll-off (time to reach $100 \Omega, \mathrm{t}_{100-\Omega}$ ) showed relatively similar values at $50 \mathrm{~V}(450-479 \mathrm{~s})$, with the highest value for AuNPs at 10\%. The delay in roll-off implied a longer ablation time and hence a greater amount of delivered energy. In terms of coagulation zone size, transverse coagulation diameter values increased with dopant concentration, from $2.6 \mathrm{~cm}$ for ND to $4.4 \mathrm{~cm}$ for AuNPs at $10 \%$ and in this case the coagulation volume tended to be more spherical (see Fig. 1). When applied voltage was increased to 70 and $90 \mathrm{~V}$, roll-off occurred earlier and coagulation zones were smaller, especially due to the reduced transverse diameter, since the axial diameter was almost unaffected by the applied voltage.

Table 3 shows the results of the 3-cm doped zone for 50, 70 and $90 \mathrm{~V}$ RFA up to rolloff, with the associated temperature distributions in Fig. 2. Initial impedance declined as dopant concentration increased and reached lower values than the $2-\mathrm{cm}$ doped zone, with shorter roll-off times. Table 4 shows the results of the 4-cm doped zone at 50, 70 and $90 \mathrm{~V}$ RFA up to roll-off, with the associated temperature distributions in Fig. 3. Initial impedance was even lower than in the 3-cm doped zone and declined as dopant concentration increased. Times to roll-off were even shorter than in the 3-cm doped zone

Table 2 Results of the RFA for different values of applied voltage on a 2-cm spherical zone in case of non-doped tissue (ND) and two types of dopants: saline solution $(0.9 \% \mathrm{NaCl})$ and AuNPs (0.01 wt\%)

\begin{tabular}{|c|c|c|c|c|c|c|c|c|c|c|}
\hline \multirow[t]{2}{*}{ Dopant } & \multirow[t]{2}{*}{$Z_{i}(\Omega)$} & \multicolumn{3}{|l|}{$50 \mathrm{~V}$} & \multicolumn{3}{|l|}{$70 \mathrm{~V}$} & \multicolumn{3}{|l|}{$90 \mathrm{~V}$} \\
\hline & & $t_{100-\Omega}$ & $B$ & $A$ & $t_{100-\Omega}$ & $B$ & $A$ & $t_{100-\Omega}$ & $B$ & $A$ \\
\hline ND & 87.7 & 457 & 2.7 & 4.4 & 94.5 & 1.6 & 3.8 & 31.5 & 1.0 & 3.7 \\
\hline \multicolumn{11}{|l|}{$\mathrm{NaCl}$} \\
\hline $1 \%$ & 84.6 & 454 & 2.8 & 4.3 & 95 & 1.7 & 4.0 & 35 & 1.2 & 3.7 \\
\hline $2 \%$ & 82 & 452 & 2.8 & 4.3 & 97.5 & 1.7 & 4.0 & 35.5 & 1.2 & 3.7 \\
\hline $5 \%$ & 75.5 & 457 & 3.1 & 4.6 & 103 & 1.9 & 4.0 & 36 & 1.3 & 3.8 \\
\hline $10 \%$ & 67.8 & 450 & 3.5 & 5.0 & 109.5 & 2.2 & 4.2 & 37.5 & 1.3 & 3.9 \\
\hline \multicolumn{11}{|l|}{ AuNPs } \\
\hline $1 \%$ & 78 & 456 & 3.0 & 4.5 & 101 & 1.8 & 4.0 & 35.5 & 1.2 & 3.6 \\
\hline $2 \%$ & 71.5 & 451 & 3.2 & 4.7 & 106.5 & 2.0 & 4.1 & 36.5 & 1.3 & 3.8 \\
\hline $5 \%$ & 60 & 448 & 3.7 & 4.8 & 120.5 & 2.6 & 4.2 & 41 & 1.5 & 4.0 \\
\hline $10 \%$ & 51.6 & 479 & 4.4 & 5.0 & 144 & 3.2 & 4.4 & 49.5 & 2.3 & 4.0 \\
\hline
\end{tabular}

$Z_{\mathrm{i}}$ : initial impedance; $t_{100-\Omega}$ : time until roll-off (in s); B and A: transverse and axial diameters (in $\mathrm{cm}$ ) of the coagulation zone, respectively. The different values of concentration (from 1 to $10 \%$ are volume fraction) 


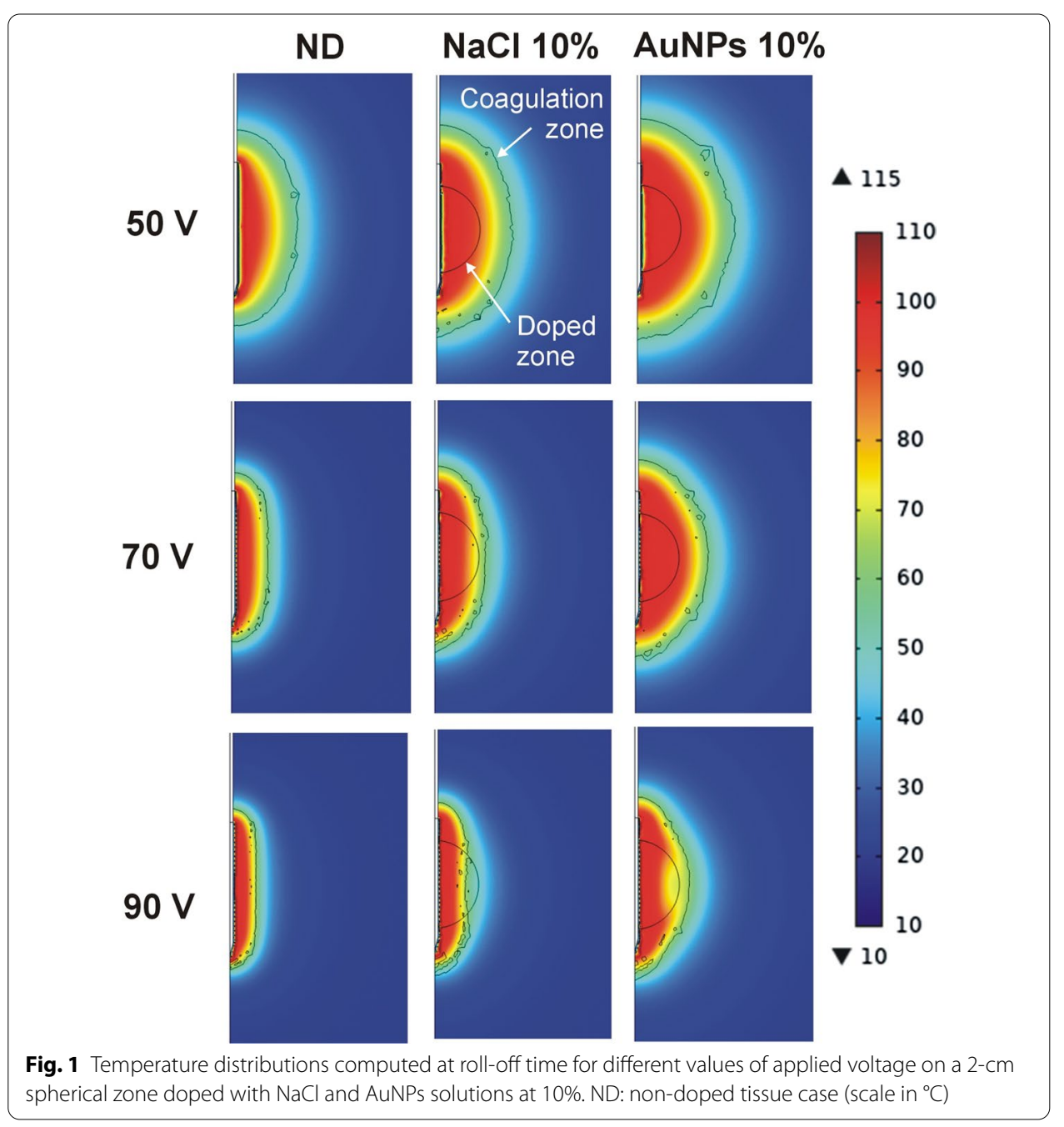

Table 3 Results of the RFA for different values of applied voltage on a 3-cm spherical zone in case of non-doped tissue (ND) and two types of dopants: saline solution $(0.9 \% \mathrm{NaCl})$ and AuNPs (0.01 wt\%)

\begin{tabular}{|c|c|c|c|c|c|c|c|c|c|c|}
\hline \multirow[t]{2}{*}{ Dopant } & \multirow[t]{2}{*}{$Z_{i}(\Omega)$} & \multicolumn{3}{|l|}{$50 \mathrm{~V}$} & \multicolumn{3}{|l|}{$70 \mathrm{~V}$} & \multicolumn{3}{|l|}{$90 \mathrm{~V}$} \\
\hline & & $t_{100-\Omega}$ & $B$ & $A$ & $t_{100-\Omega}$ & $B$ & $A$ & $t_{100-\Omega}$ & $B$ & $A$ \\
\hline ND & 87.7 & 465.5 & 2.7 & 4.4 & 94.5 & 1.6 & 3.8 & 31.5 & 1.0 & 3.7 \\
\hline \multicolumn{11}{|l|}{$\mathrm{NaCl}$} \\
\hline $1 \%$ & 82.5 & 438 & 2.6 & 4.4 & 92 & 1.8 & 3.9 & 32 & 1.2 & 3.8 \\
\hline $2 \%$ & 78 & 421.5 & 2.7 & 4.5 & 90 & 1.8 & 4.0 & 31.5 & 1.2 & 3.8 \\
\hline $5 \%$ & 67.7 & 392 & 2.7 & 4.6 & 86.5 & 1.8 & 4.2 & 30 & 1.2 & 3.8 \\
\hline $10 \%$ & 57 & 382 & 3.1 & 4.8 & 87 & 1.8 & 4.2 & 30.5 & 1.3 & 3.9 \\
\hline \multicolumn{11}{|l|}{ AuNPs } \\
\hline $1 \%$ & 71.7 & 402 & 2.7 & 4.5 & 88 & 1.8 & 4.1 & 30.5 & 1.3 & 3.7 \\
\hline $2 \%$ & 62 & 385 & 3.0 & 4.8 & 86.5 & 1.8 & 4.2 & 30 & 1.3 & 3.8 \\
\hline $5 \%$ & 47.6 & 399.5 & 3.0 & 4.8 & 97.8 & 1.9 & 4.3 & 34 & 1.3 & 4.0 \\
\hline $10 \%$ & 38 & 468 & 4.5 & 5.5 & 126.5 & 2.5 & 4.8 & 43.5 & 1.7 & 4.2 \\
\hline
\end{tabular}

$Z_{\mathrm{i}}$ : initial impedance; $t_{100-0}$ : time until roll-off (in $\left.\mathrm{s}\right) ; B$ and $A$ : transverse and axial diameters (in $\mathrm{cm}$ ) of the coagulation zone, respectively. The different values of concentration (from 1 to $10 \%$ are volume fraction) 


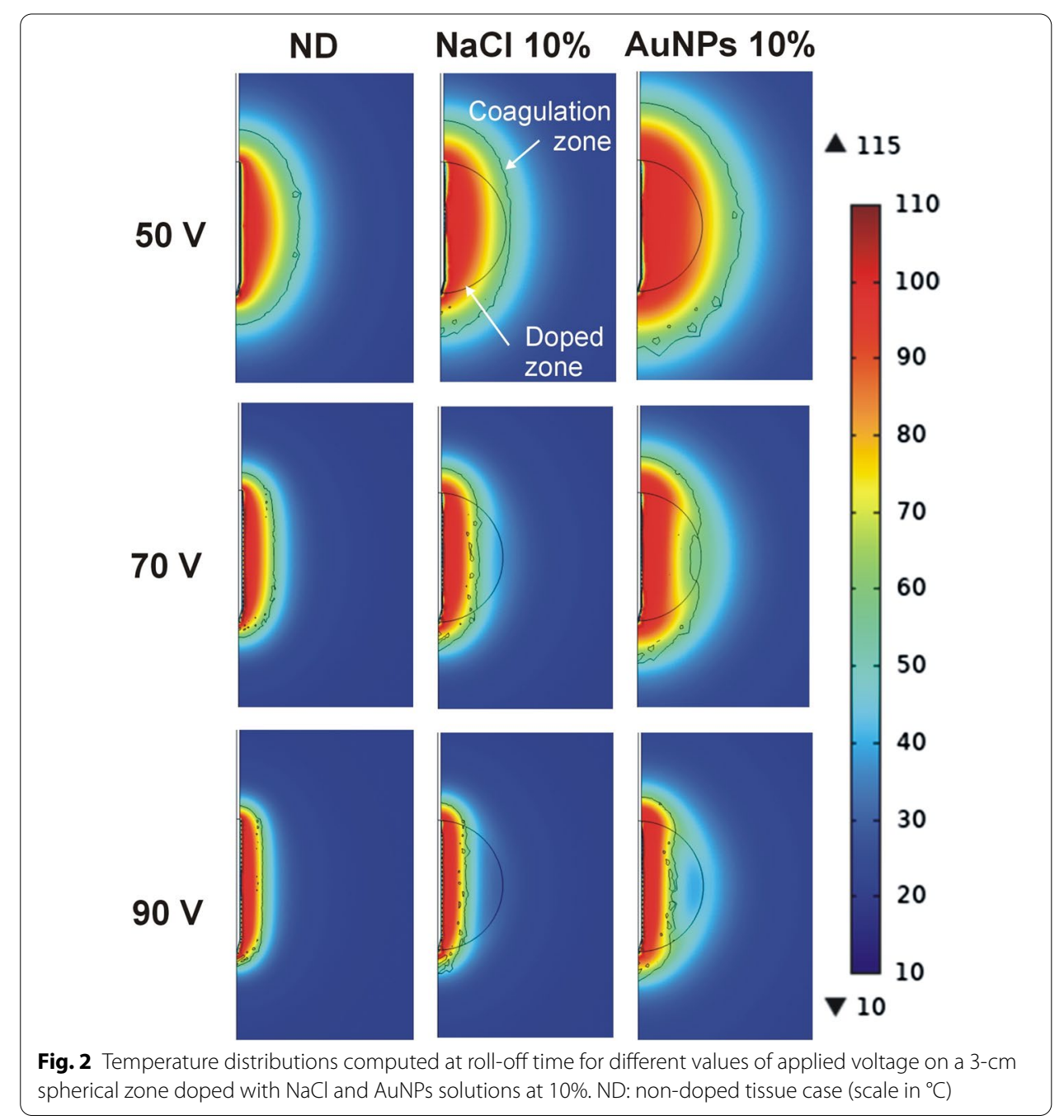

Table 4 Results of the RFA for different values of applied voltage on a 4-cm spherical zone in case of non-doped tissue (ND) and two types of dopants: saline solution $(0.9 \% \mathrm{NaCl})$ and AuNPs (0.01 wt\%)

\begin{tabular}{|c|c|c|c|c|c|c|c|c|c|c|}
\hline \multirow[t]{2}{*}{ Dopant } & \multirow[t]{2}{*}{$Z_{\mathrm{i}}(\Omega)$} & \multicolumn{3}{|l|}{$50 \mathrm{~V}$} & \multicolumn{3}{|l|}{$70 \mathrm{~V}$} & \multicolumn{3}{|l|}{$90 \mathrm{~V}$} \\
\hline & & $t_{100-\Omega}$ & B & A & $t_{100-\Omega}$ & $B$ & $A$ & $t_{100-\Omega}$ & $B$ & $A$ \\
\hline ND & 87.7 & 440 & 2.7 & 4.4 & 94.5 & 1.6 & 3.8 & 31.5 & 1.0 & 3.7 \\
\hline \multicolumn{11}{|l|}{$\mathrm{NaCl}$} \\
\hline $1 \%$ & 81.4 & 400 & 2.7 & 4.4 & 87 & 1.6 & 3.9 & 30 & 1.2 & 3.6 \\
\hline $2 \%$ & 76 & 367 & 2.6 & 4.4 & 80 & 1.7 & 3.9 & 29 & 1.2 & 3.6 \\
\hline $5 \%$ & 64 & 306 & 2.5 & 4.3 & 66 & 1.7 & 3.9 & 25.5 & 1.2 & 3.6 \\
\hline $10 \%$ & 52 & 269 & 2.5 & 4.4 & 55 & 1.7 & 3.8 & 22.5 & 1.2 & 3.4 \\
\hline \multicolumn{11}{|l|}{ AuNPs } \\
\hline $1 \%$ & 69 & 327 & 2.5 & 4.4 & 71 & 1.7 & 3.9 & 27 & 1.2 & 3.6 \\
\hline $2 \%$ & 58 & 287 & 2.5 & 4.4 & 60 & 1.7 & 3.9 & 23.5 & 1.2 & 3.6 \\
\hline $5 \%$ & 42 & 245 & 2.5 & 4.4 & 50.5 & 1.6 & 3.8 & 20.5 & 1.2 & 3.6 \\
\hline $10 \%$ & 31.9 & 265 & 2.6 & 4.9 & 54.5 & 1.7 & 3.9 & 21.5 & 1.2 & 3.6 \\
\hline
\end{tabular}

$Z_{i}$ : initial impedance; $t_{100-0}$ : time until roll-off (in s); $B$ and $A$ : transverse and axial diameters (in $\mathrm{cm}$ ) of the coagulation zone, respectively. The different values of concentration (from 1 to $10 \%$ are volume fraction) 


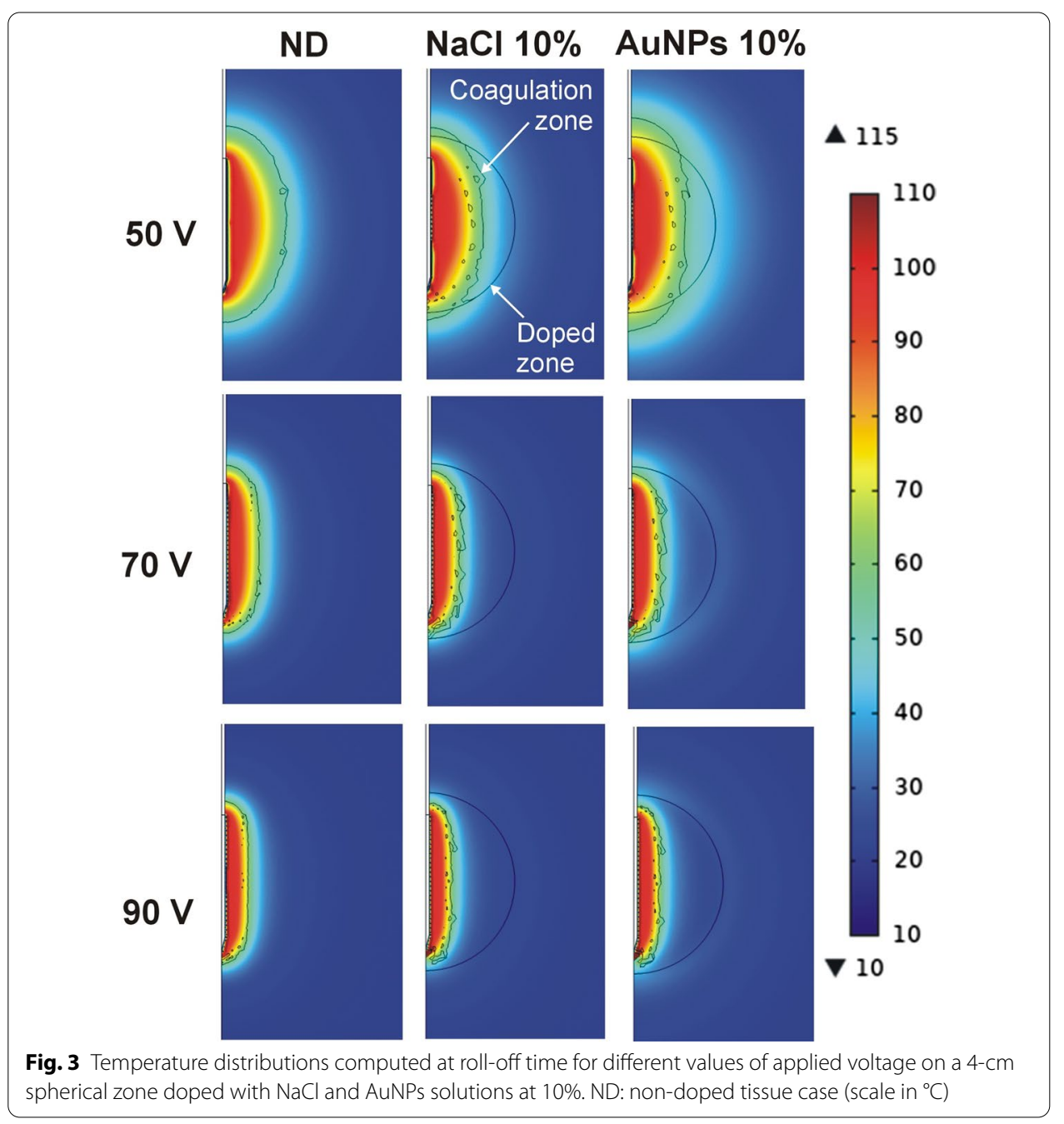

and the axial and transverse coagulation diameters were smaller, especially for $50 \mathrm{~V}$. Overall, we observed that the coagulation zone diameter decreased as the diameter of the doping zone increased.

\section{Ex vivo results}

Table 5 gives the results of the ex vivo experiments and Fig. 4 shows examples of the coagulations for each doping condition group up to roll-off, which occurred earlier for the ND ( $281 \pm 31 \mathrm{~s})$ than for AuNPs Group (432 $\pm 36 \mathrm{~s})$. There was a direct relationship between time to roll-off $\left(t_{100-\Omega}\right)$ and coagulation zone size, with the smallest diameters in the ND Group $(2.4 \pm 0.2 \mathrm{~cm})$ and the largest in the AuNPs Group $(3.7 \pm 0.3 \mathrm{~cm})$. There were no significant differences in the initial impedance of the groups: $70.7 \pm 6.3$ $\Omega, 73.2 \pm 4.0 \Omega$ and $74.4 \pm 2.4 \Omega$, for ND, $\mathrm{NaCl}$ and AuNPs Groups, respectively, which could be due to the low precision of the RF generator $( \pm 10 \%)$. When the coagulation zone reached the outer tissue surface, the transverse diameter was assessed by the radius of the deepest zone (i.e., not in contact with the surface). 
Table 5 Results of the ex vivo experiments for the three considered groups $(n=4$, mean \pm standard deviation)

\begin{tabular}{llll}
\hline Group & \multicolumn{2}{l}{ Coagulation diameters } & $\boldsymbol{t}_{\text {roll-off }}(\mathbf{s})$ \\
\cline { 2 - 3 } & Transverse $(\mathbf{c m})$ & Axial $\mathbf{( c m )}$ & \\
\hline $\mathrm{ND}$ & $2.4 \pm 0.2$ & $3.4 \pm 0.5$ & $281 \pm 31$ \\
$\mathrm{NaCl}$ & $3.0 \pm 0.4$ & $3.7 \pm 0.4$ & $379 \pm 12$ \\
AuNPs & $3.7 \pm 0.3$ & $4.1 \pm 0.2$ & $432 \pm 36$ \\
\hline
\end{tabular}

$t_{\text {roll-off: }}$ time until roll-off (at which point the ablation ceased). ND Group: non-doped tissue; NaCl Group: infusion of $2 \mathrm{~mL}$ of $0.9 \% \mathrm{NaCl} ;$ AuNPs Group: infusion of $2 \mathrm{~mL}$ of $0.1 \mathrm{wt} \%$. AuNPs

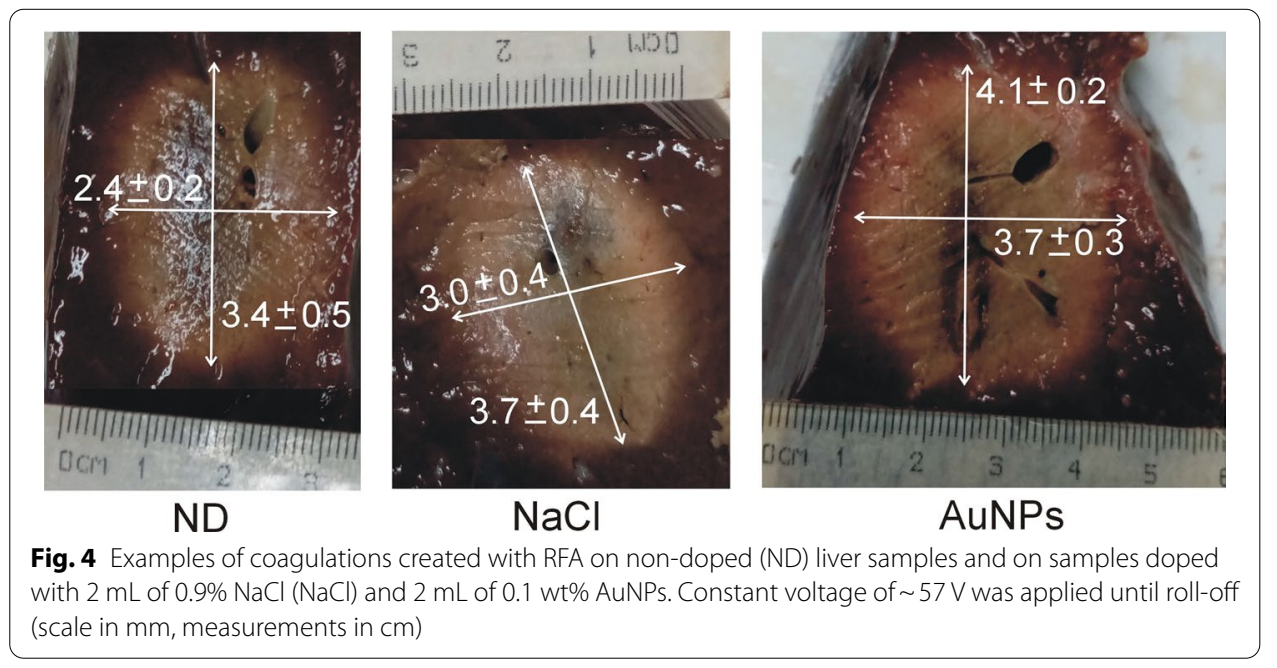

We also conducted computer simulations mimicking the applied voltage used during the ex vivo experiments $(57 \mathrm{~V})$. When a 2 - $\mathrm{cm}$ doped zone was assumed, the transverse diameter of the coagulation zone was $2.2 \mathrm{~cm}$ for ND, while it ranged from 2.4 to $2.9 \mathrm{~cm}$ for $\mathrm{NaCl}$, and from 2.6 to $3.8 \mathrm{~cm}$ for AuNPs (for concentrations of both dopants varying from 1 to $10 \%)$. These values were very similar to those obtained in the experiments. In contrast, the times to roll-off predicted by the computer model $(222-289 \mathrm{~s})$ were in general shorter than those measured in the ex vivo experiments $(281-432 \mathrm{~s})$. When larger doped zones were considered (3- and 4-cm diameters) the model predicted smaller transverse diameters than those obtained in the ex vivo experiments.

\section{Discussion}

The first step was to assess how the properties of the doped substrate changed with dopant type and concentration. Two fluid-based dopants were considered, normal saline and colloidal gold. While saline infusion has been clinically used at different concentrations to dope RFA target tissue [12,20], colloidal gold is little used in clinical practice [21]. The use of a fluid-based dopant before and during RFA is associated with the following two phenomena: (1) higher substrate electrical conductivity, especially if hypertonic saline ( $>3 \%$ ) is used instead of normal saline ( $0.9 \%)$; and (2) roll-off is delayed due to rehydration of the desiccated tissue (only with continuous infusion or periodic administration of bolus during RFA [20]). Only the first of these was considered in the present 
study, since we assumed that doping was by infusion before RFA (i.e., by pre-injection), in which case the dopant is only expected to alter the substrate properties.

Although some authors [22] have suggested that NPs could significantly raise the substrate thermal conductivity by up to $\sim 23 \%$, this would only be true at very high concentrations (e.g., 4\% volume fraction [22]). In fact, our theoretical estimates (see Table 6) showed that the volume occupied by the NPs is much smaller, e.g., $5 \times 10^{-5} \%$ when $10 \%$ colloidal gold $(0.01 \mathrm{wt} \%)$ is infused into the substrate. Our estimates (see "Computer modeling of RFA in a doped zone" section) therefore showed that only the electrical conductivity is substantially modified by the effect of saline and colloidal gold-based dopants, at least at the concentrations considered here (less than $10 \mathrm{wt} \%$ ). This is in agreement with previous estimates of the properties of saline-mixed tissue, when electrical conductivity was seen to change drastically with the saline:tissue mixing ratio while the thermal conductivity hardly changed [23].

Although the electrical properties of colloidal gold have previously been evaluated [24], no study has so far evaluated the electrical conductivity of AuNPs-substrate mixtures. Our data, shown in Table 6, provide guiding values on how the electrical conductivity of a substrate doped with colloidal gold could change at different weight concentrations between 1 and $10 \%$. It is reasonable to assume that a higher concentration of doping agent in the substrate $(>10 \%)$ and other more conductive types of dopants (e.g., hypertonic saline or $>0.01 \mathrm{wt} \%$ colloidal gold) would provide higher electrical conductivity values.

Once it was found that the addition of nanofluid (normal saline or colloidal gold 0.01 wt $\%)$ to a substrate at concentrations between 1 and $10 \%$ only modified its electrical conductivity, we explored how this could alter the electrical and thermal performance of a spherical doped zone during RFA. For this, we built a numerical model based on a doped zone surrounded by non-doped tissue, i.e., similar to a two-compartment model, as proposed in $[25,26]$. These models have already shown that the presence of a tumor with higher electrical conductivity than the surrounding tissue provides very different temperature distributions than models based on homogeneous tissue (one-compartment models) $[25,26]$. They also suggested that the maximum voltage applied before roll-off is

Table 6 Estimation of the characteristics of the tissue doped with different concentrations (C, volume fraction) of a solution of $0.01 \%$ (wt) AuNPs and a solution $0.9 \% \mathrm{NaCl}$

\begin{tabular}{llllll}
\hline Dopant & $\boldsymbol{C}(\%)$ & $\boldsymbol{\Phi}_{\mathbf{D}}\left(\mathbf{\times} \mathbf{1 0}^{\mathbf{- 9}}\right)$ & $\boldsymbol{\sigma}(\mathbf{S} / \mathbf{m})$ & $\boldsymbol{c}(\mathbf{J} / \mathbf{k g ~ K})$ & $\boldsymbol{k}(\mathbf{W} / \mathbf{m ~ K})$ \\
\hline \multirow{2}{*}{$0.9 \% \mathrm{NaCl}$} & 0 (non-doped) & 0 & 0.2 & 3455 & 0.502 \\
& 1 & - & 0.219 & 3455 & 0.502 \\
& 2 & - & 0.238 & 3455 & 0.502 \\
& 5 & - & 0.297 & 3455 & 0.502 \\
0.01 wt\% AuNPs & 10 & - & 0.394 & 3455 & 0.502 \\
& 1 & 54.15 & 0.271 & 3455 & 0.502 \\
& 2 & 108.30 & 0.342 & 3455 & 0.502 \\
& 5 & 270.75 & 0.555 & 3455 & 0.502 \\
& 10 & 541.50 & 0.910 & 3455 & 0.502
\end{tabular}

$\sigma$ : electrical conductivity, $c$ : specific heat, $k$ : thermal conductivity, tissue properties estimated at $37^{\circ} \mathrm{C}$. In the case of AuNPs $\sigma$ was estimated using the $\Phi_{\mathrm{D}}$ value (volume fraction of solid AuNPs within the doped tissue); while that in the case of $\mathrm{NaCl} \sigma$ was estimated using Eq. (1) proposed in [9] 
different for different sized tumors and reduces as tumor diameter increases [26]. None of the previous models considered different tissue doping conditions or assessed the effect of doped zone size in relation to electrode length.

Our computational results showed that in the non-doped (ND) tissue model the relationship between doped zone diameter and electrode length determines RFA electrical and thermal performance. As the doped zone size exceeds the electrode length (i.e., the electrode is completely inside the doped zone, as in the 4-cm case), the temperature distribution is more similar to the homogeneous tissue RFA case, i.e., electrical power deposition (or current density) and heating mainly occur at the edges of the electrode (see Fig. 3). This is known as the edge effect and greatly limits the growth of the transverse diameter and sphericity of the coagulation zone.

On the other hand, we also found that if the electrode length exceeds the doped zone diameter and the edges of the electrode are outside the doped zone (as in the 2-cm case), the edge effect is in some way compensated for by the high electrical conductivity of the doped zone, which means that the current density is higher in the central zone than at the edges, where independent heating zones can be seen in the first few seconds (see Fig. 1). This behavior was amplified by the presence of a highly conductive dopant, insofar as the current density was greater than in the non-doped tissue case. As a result, the computational results shown in Figs. 1, 2, 3 suggest that the following procedure would be an effective way of ablating a spherical tumor: (1) electrode longer than the tumor diameter (e.g., $1 \mathrm{~cm}$ longer), (2) tumor in the central area of the electrode, i.e., distal and proximal edges surrounded by healthy tissue, and (3) tumor doped with a sufficiently high concentration of conductive agents (for example, 10\% AuNPs $0.01 \mathrm{wt} \%$ ). This would create relatively spherical coagulation zones capable of destroying the tumor plus a safety margin (see Fig. 1). From an oncological point of view, we recognize that traversing the tumor with the sharp tip of the electrode and exceeding its limits would imply a clear risk of needle track seeding prior to RFA (i.e., tumor cell spread [27]). However, it is also true that the tissue adjacent to the tip will most certainly be ablated, greatly reducing this risk.

Our results also suggest that when RFA is performed on highly conductive substrates (note that this may be valid both for tumors doped with a conductive substance and for non-doped tumors with much higher conductivity than the surrounding tissue), larger coagulation zone volumes can be created at low voltages $(50 \mathrm{~V})$. However, moderate and high voltages $(70$ and $90 \mathrm{~V}$ ) can quickly heat the tissue but involve the risk of early rolloff, which notably limits the growth of the coagulation zone transverse diameter (see Figs. 1, 2, 3). This fast RFA heating on a highly conductive substrate was demonstrated by Ji et al.[28] in an ex vivo study in which the evolution of tissue temperature at 1 and $2 \mathrm{~cm}$ from the electrode was recorded. Both our computer and experimental results (see Table 1 and Fig. 4) suggest that when the electrical conductivity of the dopant is raised, the transverse diameter is larger than the axial diameter, so that the coagulation zone is more spherical, which is in agreement with Ji et al.'s results [28]. However, their experimental setup and ours share the uncertainty about the exact distribution of the dopant around the electrode. For this reason, our computer results suggest that in both experimental models the dopant was possibly concentrated in the central electrode zone, thus achieving preferential heating in that zone, plus a more spherical coagulation zone. 
Our conclusion on the recommended use of low voltage instead of high voltage goes in the opposite direction to the impedance-controlled pulsed protocol, which employs high-voltage pulses and is broadly used in clinical practice. This protocol was demonstrated to be better than a low-voltage continuous protocol in a classical work by Goldberg et al.[29], later improved on by Solazzo et al.[30]. However, these studies used homogenous tissue, i.e., a non-doped target. Other experimental studies on RFA combined with saline infusion could deliver RF power at a high voltage with few roll-offs [31]. In fact, our clinical experience of ablating tumors smaller than $2 \mathrm{~cm}$ with a $3-\mathrm{cm}$ electrode with hypertonic saline infusion only in the central electrode zone showed that it was possible to deliver power without roll-offs when an extra bolus is infused after $4 \mathrm{~min}$ [20]. The discrepancy of these results with those from our model is that the dopant fluid possibly provides an extra hydration effect which could be the partial cause of the roll-off delay, as we modeled in [32]. Our computer results call attention to the need to explore optimized protocols for the case of substrates doped with highly conductive fluids and suggest that in these cases the relationship between electrode length and tumor size could condition the result in terms of coagulation zone volume.

Our computer and ex vivo results showed good agreement in terms of coagulation zone transverse diameter when we assumed a 2-cm-diameter doped zone, which suggests that during ex vivo experiments the dopant possibly extended in an area of that size. The times until roll-off predicted by the computer model were shorter than those observed during the ex vivo experiments. This could be due to the fact that the computer model did not include the possible rehydration effect of the doping fluid, which has been shown to slightly delay the appearance of the roll-off [32].

Finally, although there are still no data available on the advantages of nanofluids over saline to dope targets, it should not be forgotten that there are serious risks associated with infusing large amounts of fluid in RFA [33], and it seems reasonable to suggest that higher electrical conductivity should be achieved with the smallest possible amount of fluid.

\section{Limitations}

Some limitations should be pointed out. First, our theoretical estimations showed that the presence of either $\mathrm{NaCl}$ or AuNPs at the concentrations considered only affected the electrical characteristics of the substrate. This might not be valid with fluids at higher concentrations (i.e., $>0.9 \%$ in case of $\mathrm{NaCl}$, and $>0.01 \mathrm{wt} \%$ in case of colloidal gold) or when the substrate is doped with higher concentrations of dopant fluid (i.e.,>10\%). It is also important to point out that the theoretical estimates of density, volumetric heat specific and thermal conductivity of the doped substrate were based on expressions that have been proposed to study tissues with variable water content [34]. Second, our modeling study assumed that the dopant was spherically distributed around the electrode. This should be seen as a first approximation to the real situation, which could be different in the case of a heterogeneous tissue in which blood vessels could preferentially evacuate the dopant agent [35]. Third, our model considered that electrical conductivity of doped substrates dropped 2 orders of magnitude once temperature reached $100{ }^{\circ} \mathrm{C}$. However, there are no experimental data available on electrical conduction through desiccated tissues previously doped with AuNPs, i.e., we do not yet know if the 'dry residue' 
formed by the NPs themselves can conduct the RF current in any way. And fourth, Eqs. (1) and (2) which relate the electrical conductivity $(\sigma)$ of the doped substrate with the dopant concentration (AuNP or $\mathrm{NaCl}$ ) were really built from very little experimental data, which also have an associated uncertainty. Furthermore, we are also not completely sure that the relationships are necessarily linear. In this regard, future experimental studies should be carried out to establish more accurately the relationship between dopant concentrations and the resulting electrical conductivity, especially under conditions of perfusion of blood (in vivo) and tumor tissue. As a consequence, since our study did not assess the impact of these limitations by means of sensitivity analyses, we recognize that our conclusions could be different in the case of being able to have more exact relationships between $\sigma$ and dopant concentration.

\section{Conclusions}

The theoretical analysis showed that the addition of normal saline or colloidal gold (0.01 $w t \%)$ at concentrations lower than $10 \%$ only modify the electrical conductivity of the doped substrate and have very little effect on the thermal characteristics. The computer results showed a relationship between doped zone size and electrode length regarding the created coagulation zone, and that highly conductive doped substrates possibly require low voltages to obtain large spherical coagulation zones. Both computer and ex vivo experiments showed that doping with AuNPs can enlarge the coagulation zone, especially the transverse diameter, hence achieving more spherical coagulation zones. These findings indicate that fluid-based dopants produce larger coagulation zones by delaying the first roll-off, which suggests that combining RFA with tumor doping could improve current ablation techniques by achieving complete coagulation of the tumor zone with a single application, i.e., without overlap due to repositioning of the electrodes.

\section{Methods}

\section{Electrical characterization of the doped substrates}

In order to quantify changes in electrical conductivity of a substrate doped with a small amount of normal saline or AuNPs colloidal solution we built tissue-mimicking phantoms based on agar gel (constituted by deionized water and $2 \mathrm{~g} / \mathrm{mL}$ agar-agar powder). The phantoms had two compartments: a sphere mimicking a 4-cm doped zone, and a cylinder enclosing the sphere and mimicking non-doped tissue (see Fig. 5a). The sphere was located in the center of the cylinder.

While the cylinder was always made of agar gel, the spherical compartment was doped with one of two solutions: either $0.9 \% \mathrm{NaCl}$ (Pisa Pharmaceutics, Guadalajara, Mexico) or $0.01 \mathrm{wt} \%$ colloidal AuNPs solution (10 $\mathrm{nm}$ average diameter) provided by the Physics Institute of UASLP (San Luis Potosí, Mexico). We assumed that these two dopant solutions did not occupy the entire doped area, but only a small percentage. In order to simulate this diffusion of the dopant in the medium, we considered two values for saline ( 1 and $1.5 \% \mathrm{wt}$ ) and one for colloidal gold (1\% wt). For this we built four different spherical pieces to model four different conditions of the doped zone: (1) identical to the rest of the phantom (i.e., non-doped tissue, using a $33.5 \mathrm{~cm}^{3}$ agar gel volume); (2) spherical zone doped with $1 \mathrm{wt} \%$ of $\mathrm{NaCl}$ (using a mixture with $0.83 \mathrm{~g}$ of agar powder and $0.3 \mathrm{~cm}^{3}$ of $0.9 \% \mathrm{NaCl}$ ); (3) spherical zone doped with $1.5 \mathrm{wt} \%$ of $\mathrm{NaCl}$ (using a mixture with $0.8 \mathrm{~g}$ 

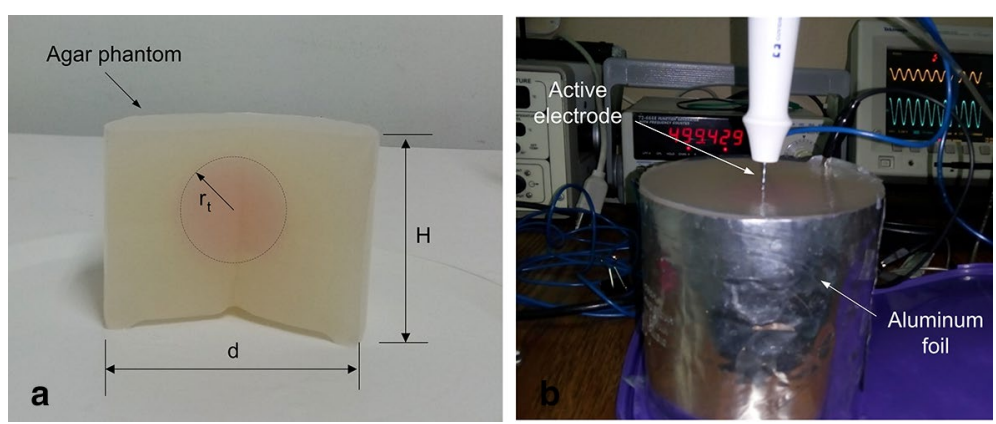

Fig. 5 a Agar phantoms were based on a sphere of radius $r_{t}=2 \mathrm{~cm}$ (dotted line) located at the center of a cylinder of diameter $d=10 \mathrm{~cm}$ and height $\mathrm{H}=11 \mathrm{~cm}$. Note that a circular fragment of the cylinder has been removed to facilitate the observation of the central sphere. $\mathbf{b}$ Experimental setup used to electrically characterize each phantom, including an RF applicator (active electrode) inserted into the center of the sphere doped with $\mathrm{NaCl}$ or AuNPs. The entire phantom was surrounded by a 2-mm-thick aluminum foil that acted as a dispersive electrode

of agar powder and $0.5 \mathrm{~cm}^{3}$ of $0.9 \% \mathrm{NaCl}$ ); and (4) spherical zone doped with $1 \mathrm{wt} \%$ of AuNPs solution (using a mixture with $0.83 \mathrm{~g}$ of agar powder and $0.01 \mathrm{wt} \%$ AuNPs solution). For the doped sphere, the liquid components (deionized water $\sim 80^{\circ} \mathrm{C}$ and saline solution or AuNPs as appropriate) were mixed in a glass container together with the agar powder $(2 \mathrm{~g} / \mathrm{mL})$. To ensure the homogeneity of the sample, the mixture was kept on a magnetic stirrer at constant temperature for $1 \mathrm{~h}$. It was then poured into 4-cm-diameter spherical containers and kept at a temperature of $10^{\circ} \mathrm{C}$ for $12 \mathrm{~h}$ to ensure solidification.

The cylindrical compartment was made in two stages. Agar powder $(2 \mathrm{~g} / \mathrm{mL})$ was first mixed in deionized water at $80{ }^{\circ} \mathrm{C}$, maintaining a constant temperature and stirring for $1 \mathrm{~h}$. Subsequently, it was poured into a cylindrical container with an internal diameter of $10 \mathrm{~cm}$ and a height of $15 \mathrm{~cm}$ up to a third of its volume, allowing it to solidify at room temperature. Prior to complete solidification, the doped sphere was placed in the center of the cylinder and covered with the agar powder and deionized water mixture up to $11 \mathrm{~cm}$ in height. Once solidified, the entire phantom was kept in refrigeration at $10^{\circ} \mathrm{C}$ at least $12 \mathrm{~h}$ before experiments.

To estimate the electrical conductivity $(\sigma)$ of the doped zone, we measured the impedance $Z$ between a 3-cm active electrode model Cool-Tip (Medtronic, Minneapolis, MN, USA) inserted in the center of the spherical piece and a 2-mm-thick aluminum foil entirely surrounding the phantom and acting as a dispersive electrode (Fig. $5 \mathrm{~b}$ ). $Z$ measurements were conducted by applying a sine voltage of $2 \mathrm{~V}$ amplitude and $500 \mathrm{kHz}$ frequency. Voltage and current were measured by a digital oscilloscope TDS 3034B and a current probe mode A622, both from Tektronix (Beaverton, OR, USA). As expected, at RF frequencies the phantoms behaved electrically as pure resistors (no phase shift between current and voltage was observed), so that $Z$ was inversely related to $\sigma$. Once $\mathrm{Z}$ measurements were obtained, we built a theoretical model and conducted computer simulations by changing $\sigma$ values until we obtained the same $Z$ values (i.e., a trial and error approach was used to estimate $\sigma$ ). The geometry, size and electrical boundary conditions of the theoretical model exactly mimicked the experimental conditions. Figure 6a shows the boundary conditions used. One-way analysis of variance was performed by the Fisher test $(\mathrm{P}=0.05)$ to compare the $Z$ values obtained with the four groups. 


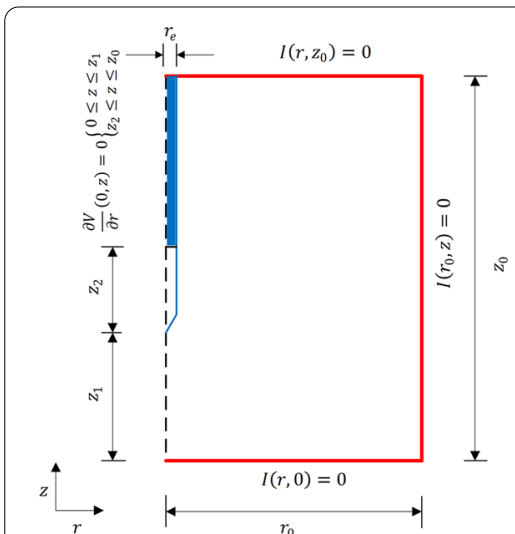

a

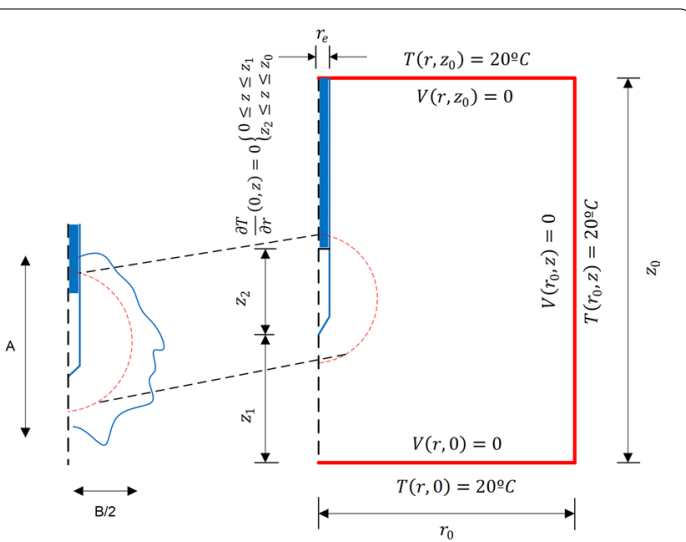

b

Fig. 6 a Geometry and boundary conditions of the theoretical model used to estimate the values of electrical conductivity associated with the doped zone in the agar phantoms. Dimensions: $r_{0}=50 \mathrm{~mm}$, $z_{0}=110 \mathrm{~mm}, r_{\mathrm{i}}=0.75 \mathrm{~mm}, z_{1}=40 \mathrm{~mm}, z_{2}=70 \mathrm{~mm} . V_{i}=2 \mathrm{~V} . \mathbf{b} 2 \mathrm{D}$ axisymmetric model used to study the temperature distributions during RF ablation of a doped zone with different dopants. It consisted of a cylinder of non-doped liver tissue (radius $r_{0}=10 \mathrm{~cm}$ and height $z_{0}=16 \mathrm{~cm}$ ) surrounding a spherical doped zone of variable radius (dashed red line, $r_{\mathrm{t}}=2,3$ and $4 \mathrm{~cm}$ ). The active electrode $\left(r_{\mathrm{e}}=0.75 \mathrm{~mm}\right.$ ) is inserted into the center of the doped zone. Solid blue line represents the contour of the coagulation zone, and $A$ and $B$ are the axial and transverse diameters, respectively

Table 7 Characteristics of the materials used in the computational model [20]

\begin{tabular}{lclcl}
\hline Material & $\boldsymbol{\rho}\left(\mathbf{k g} / \mathbf{m}^{\mathbf{3}}\right)$ & $\boldsymbol{\sigma}(\mathbf{S} / \mathbf{m})$ & $\boldsymbol{c}(\mathbf{J} / \mathbf{k g ~ K})$ & $\boldsymbol{k}(\mathbf{W} / \mathbf{m ~ K})$ \\
\hline Healthy tissue & 1080 & 0.2 & 3455 & 0.502 \\
Metal (electrode) & 8000 & $7.4 \cdot 10^{6}$ & 480 & 18 \\
Plastic (insulated trocar) & 70 & $10^{-5}$ & 1045 & 0.026 \\
\hline
\end{tabular}

$\rho$ : density, $\sigma$ : electrical conductivity, $c$ : specific heat, $k$ : thermal conductivity. Tissue properties assessed at $37^{\circ} \mathrm{C}$

\section{Computer modeling of RFA in a doped zone}

Computer modeling was used to study the effects of doping a tissue zone with $\mathrm{NaCl}$ and AuNPs on RFA electrical and thermal performance. Computer models were built and solved by finite element method using COMSOL Multiphysics software (Burlington, MA, USA). The problem represented a 2D axis symmetric model (see Fig. 6b) and consisted of a cylindrical domain mimicking non-doped liver tissue and a spherical domain mimicking a doped zone with variable diameter $(2,3$ and $4 \mathrm{~cm})$. This sensitivity analysis was motivated by the fact that the spatial distribution of the doping agent around the electrode was not really known. It also included an RF applicator identical to the Cool-Tip applicator used in the agar and ex vivo experiments. The dispersive electrode was modeled as an electrical boundary condition $V=0$ on all the outer boundaries. The properties of the materials are shown in Table 7 [20]. The model was based on a coupled electric-thermal in which the governing equation for thermal problem was:

$$
\frac{\partial(\rho h)}{\partial t}=\nabla \cdot(k \nabla T)+q+Q_{p}
$$

where $\rho\left(\mathrm{kg} / \mathrm{m}^{3}\right)$ is tissue density, $h(\mathrm{~J} / \mathrm{kg} \cdot \mathrm{K})$ enthalpy, $k(\mathrm{~W} / \mathrm{m} \cdot \mathrm{K})$ thermal conductivity, $T$ $\left({ }^{\circ} \mathrm{C}\right)$ temperature, $t(\mathrm{~s})$ time, $q$ the heat source and $Q_{p}$ heat loss by blood perfusion (which 
is ignored since we are modeling ex vivo conditions). For biological tissues enthalpy is related to tissue temperature by the following expression [36]:

$$
\frac{\partial(\rho h)}{\partial t}=\frac{\partial T}{\partial t} \cdot \begin{cases}\rho_{l} c_{l} & 0<T \leq 99{ }^{\circ} \mathrm{C} \\ h_{f g} C & 99<T \leq 100{ }^{\circ} \mathrm{C}, \\ \rho_{g} c_{g} & T>100{ }^{\circ} \mathrm{C}\end{cases}
$$

where $\rho_{i}$ and $c_{i}$ are density and specific heat of tissue, respectively, at temperatures below $100{ }^{\circ} \mathrm{C}(i=l)$ and at temperatures above $100{ }^{\circ} \mathrm{C}(i=g), h_{f g}$ is the product of water latent heat of vaporization and water density at $100{ }^{\circ} \mathrm{C}$, and $C$ is tissue water content inside the liver (68\%) [37]. Equation (3) was applied to each region of the model by substitution of the appropriate properties. To calculate $Q_{R F}$ we solved the electrical problem, which for RFA can be calculated by:

$$
Q_{\mathrm{RF}}=\boldsymbol{J} \bullet \boldsymbol{E}=\sigma \cdot|\boldsymbol{E}|^{2}=\sigma \cdot|-\nabla V|^{2},
$$

where $\boldsymbol{J}$ is current density $\left(\mathrm{A} / \mathrm{m}^{2}\right), \boldsymbol{E}$ electrical field $(\mathrm{V} / \mathrm{m}), \sigma$ electrical conductivity $(\mathrm{S} / \mathrm{m})$ and $V$ voltage $(\mathrm{V})$. We used quasi-static approximation to solve the electromagnetic problem, where conduction currents were assumed to dominate compared to displacement currents. The electric voltage was computed by solving the equation [25]

$$
\nabla \bullet(\sigma \nabla V)=0 .
$$

We assumed that the temperature dependence of electrical conductivity for both doped zone and for non-doped tissue was determined by:

$$
\sigma(T)=\sigma_{0} \mathrm{e}^{0.15\left(T-T_{b}\right)},
$$

where sub-index $o$, indicates properties measured at $T_{b}\left(37^{\circ} \mathrm{C}\right)$. Damage to tissue is the effect of exposing it to a high temperature for a prolonged time. A traditional way to predict the probability of irreversible thermal damage is the Arrhenius reaction rate model:

$$
\Omega(t)=A \int_{0}^{t} \exp \left[-E_{a} / R T(\tau)\right] d \tau
$$

where $\Omega(t)$ is the degree of tissue death, $A$ is the frequency factor $\left(7.39 \cdot 10^{39} \mathrm{~s}^{-1}\right), E_{a}$ is the activation energy for the irreversible damage reaction $\left(2.557 \cdot 10^{5} \mathrm{~J} / \mathrm{mol}\right)$, and $R$ is the universal gas constant $(8.314 \mathrm{~J} / \mathrm{mol} \cdot \mathrm{K})$. The kinetic parameters $\left(A\right.$ and $\left.E_{a}\right)$ that accounts for the morphological changes in tissue related to the thermal degradation of proteins were taken from [25]. A value $\Omega=4.6$ (which corresponds to $99 \%$ of cell death probability) was used to compute the coagulation zone boundary.

To determine how dopant solution within the tissue modifies the temperature distributions in the tissue during RFA, $\mathrm{NaCl}$ and AuNPs were assumed to change the properties of the tissue they came into contact with. The doped substrate was always assumed to coincide with the volume of a spherical zone around the electrode. To estimate the electrical conductivities for tissue doped with $\mathrm{NaCl}$ or AuNPs we used Eqs. (1) and (2), which were obtained from the results of the experiments on the agar model (see Results section), and where $\sigma_{\mathrm{S}}$ (electrical conductivity of the non-doped substrate) was that of the non-doped tissue $(0.2 \mathrm{~S} / \mathrm{m}$ in Table 7). Electrical impedance was assumed to increase 
by $+1.5 \% /{ }^{\circ} \mathrm{C}$ until $100{ }^{\circ} \mathrm{C}$. To model the tissue desiccation associated with the vaporization, when temperature reached $100{ }^{\circ} \mathrm{C}$ we assumed that electrical conductivity dropped 2 orders of magnitude.

The other properties (density, volumetric heat specific and thermal conductivity) were estimated theoretically using the expression proposed in [34] for tissue characteristics according to the water content. Firstly, density of the doped tissue $\left(\rho_{\mathrm{DT}}\right)$ can be determined as:

$$
\rho_{\mathrm{DT}}=\left(1-\phi_{\mathrm{D}}\right) \rho+\phi_{\mathrm{D}} \rho_{\mathrm{D}}
$$

where $\rho$ is the density of the non-doped tissue (see Table 7), $\rho_{\mathrm{D}}$ the density of dopant $\left(\mathrm{NaCl}\right.$ solution or solid AuNPs $\left.\left(19,300 \mathrm{~kg} / \mathrm{m}^{3}\right)\right)$ and $\Phi_{\mathrm{D}}$ denotes the volume fraction of dopant within the doped tissue. In the case of AuNPs, due to the extremely low value of $\Phi_{\mathrm{D}}$ (e.g., $\sim 50 \times 10^{-9}$ in the case of $0.01 \mathrm{wt} \%$ of AuNPs occupying $1 \%$ by weight of doped tissue), $\rho_{\mathrm{DT}} \approx \rho$, i.e., doped tissue density is hardly affected by the addition of the NPs. Likewise, in the case of $\mathrm{NaCl}$ solution, due to the similarity between its density $\left(\sim 1000 \mathrm{~kg} / \mathrm{m}^{3}\right)$ and that of the tissue $\left.\left(1080 \mathrm{~kg} / \mathrm{m}^{3}\right)\right), \rho_{\mathrm{DT}} \approx \rho$, i.e., the doped tissue density is little affected by the $\mathrm{NaCl}$ solution.

Volumetric specific heat of doped tissue $(\rho c)_{\mathrm{DT}}$ can be similarly determined by:

$$
(\rho c)_{\mathrm{DT}}=\left(1-\phi_{\mathrm{D}}\right)(\rho c)+\phi_{\mathrm{D}}(\rho c)_{\mathrm{D}}
$$

where $\rho c$ is the volumetric specific heat of the non-doped tissue, and $c \rho_{\mathrm{D}}$ the volumetric specific heat of dopant. In the case of AuNPS, although the solid NPs have a much lower value $\left(129 \mathrm{~J} / \mathrm{K} \cdot \mathrm{m}^{3}\right)$ than tissue $(3455 \mathrm{~J} / \mathrm{kg} \cdot \mathrm{K})$, the extremely low value of $\Phi_{\mathrm{D}}$ implies that the volumetric specific heat of the doped tissue is not greatly affected by the AuNPs. Likewise, due to the similarity between the volumetric specific heat of the $\mathrm{NaCl}$ solution $(\sim 4090 \mathrm{~J} / \mathrm{kg} \cdot \mathrm{K}$ [38]) and the tissue, the $\mathrm{NaCl}$ solution has little effect on the volumetric specific heat of the doped tissue.

To determine the thermal conductivity in the doped tissue, we used the MaxwellEucken model [39] applied to suspension of particles:

$$
k_{D T}=k \cdot \frac{k_{D}+2 k-2 \phi_{D}\left(k-k_{D}\right)}{k_{D}+2 k+\phi_{D}\left(k-k_{D}\right)},
$$

where $k_{\mathrm{DT}}$ is a mixture of two phases, a continuous phase (the suspending liquid, nondoped tissue in our case) of conductivity $k$ is the thermal conductivity of the non-doped tissue, and a disperse phase of dopant $(\mathrm{NaCl}$ solution or gold spherical NPs of conductivity $\left.k_{\mathrm{D}}=317 \mathrm{~W} / \mathrm{m} \mathrm{K}\right)$, and the volume fraction $\Phi_{\mathrm{D}}$ of dispersal phase [40]. Once more, the extremely low value of $\Phi_{\mathrm{D}}$ means that the thermal conductivity of the doped tissue is not much affected by the AuNPs, while the similarity between the thermal conductivity of the $\mathrm{NaCl}$ solution $(\sim 0.63 \mathrm{~W} / \mathrm{m} \cdot \mathrm{K}[38])$ and the tissue $(0.502 \mathrm{~W} / \mathrm{m} \mathrm{K})$ showed that that thermal conductivity of the doped tissue was not affected by the $\mathrm{NaCl}$ solution.

We assessed the effect doping the tissue with different concentrations $C$ of $0.01 \%$ AuNPs colloidal solution, ranging from $0 \%$ (non-doped tissue) to $10 \%$. Each concentration value was a value of a volume fraction of solid AuNPs in the doped tissue $\left(\Phi_{\mathrm{D}}\right)$. Table 6 summarizes the estimated characteristics of the doped tissue for different $0.9 \%$ $\mathrm{NaCl}$ solution and Au colloidal (0.01 wt\%) concentration values distributed in the tissue 


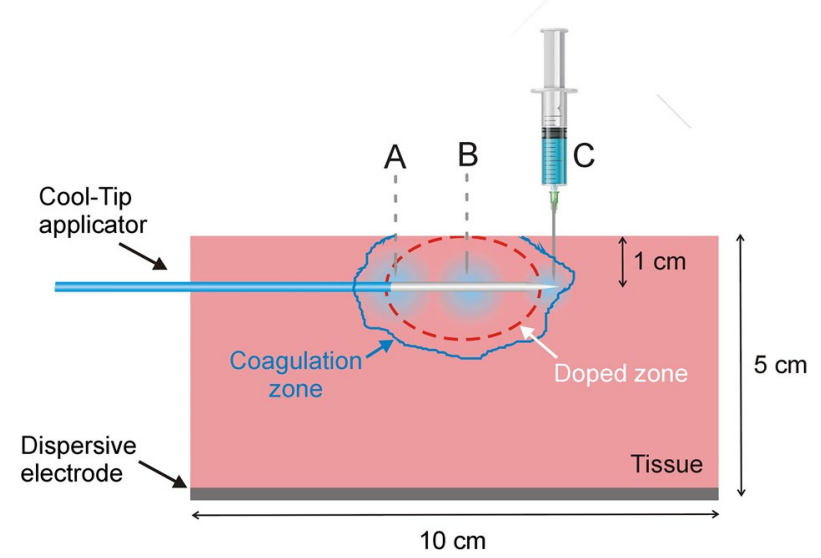

Fig. 7 Cross-sectional view of tissue sample used in the ex vivo experiments. The ablation electrode was inserted $1 \mathrm{~cm}$ below the tissue surface. A, B, and C indicate the dopant infusion points (saline solution or Au colloidal). Solid blue line would represent the contour of the coagulation zone, while dashed red line would represent the contour of the doped zone

(from 0 to $10 \%$ ). Note that only the electrical characteristics were significantly modified by the dopants while the thermal properties remain unchanged.

To study the effects of the dopants on the coagulation zone created during RFA, we simulated three values of applied voltage: 50, 70 and $90 \mathrm{~V}$. While the first (low voltage) is expected to avoid roll-offs for at least $10 \mathrm{~min}$, the third (high voltage) is the standard value used in clinical practice for pulsed protocols [41]. All three values were expected to provide a preliminary insight into the effect of the dopant in terms of delaying roll-off, which was assumed to occur when impedance reached $100 \Omega$ (initial impedance was always lower than this value). After computing the coagulation zone boundary by the $\Omega=4.6$ isoline, we computed the axial (A) and transverse (B) diameters (see Fig. 6b). Coagulation zone sphericity was assessed as A/B (values close to 1 are associated with spherical coagulation zones, while values greater than 1 are associated with ellipsoids).

\section{Ex vivo experimental setup}

The experimental setup was based on an ex vivo model at room temperature $\left(20{ }^{\circ} \mathrm{C}\right)$, which consisted of samples $(8 \times 10 \times 5 \mathrm{~cm} \pm 2 \mathrm{~cm})$ of bovine liver acquired locally. The samples were placed on a metal plate which acted as a dispersive electrode. An active electrode model Cool-tip (Medtronic, Minneapolis, MN, USA) with $1.5 \mathrm{~mm}$ outside diameter and a 3-cm-long active tip was horizontally inserted $\sim 1 \mathrm{~cm}$ into each sample (see Fig. 7). The electrode was internally cooled with circulating water (at $8 \pm 2{ }^{\circ} \mathrm{C}$ ) using a Masterflex L/S peristaltic pump (Cole-Parmer, Vernon Hills, IL, USA) at a rate of $40 \mathrm{~mL} / \mathrm{min}$. The pump was started at least $2 \mathrm{~min}$ before RFA to ensure effective cooling. Ablations were conducted by an RFG 3E-RF generator (Radionics, Burlington, MA, USA). Since the simulation results presented before suggested that highly conductive doped substrates possibly require moderate voltages, the RF generator set to $\sim 57 \mathrm{~V}$ constant voltage was applied until roll-off (a variation of $\pm 2 \mathrm{~V}$ occurred between applications, due to the imprecision of the generator itself). 
Three RFA protocols were tested: (1) non-doped tissue (ND Group), (2) previous infusion of $2 \mathrm{~mL}$ of $0.9 \% \mathrm{NaCl}$ ( $\mathrm{NaCl}$ Group), and (3) previous infusion of $2 \mathrm{~mL}$ of AuNPs $0.1 \mathrm{wt} \%$ (AuNPs Group). Note that a colloid with a higher concentration of AuNPs was used in the ex vivo experiments in case of higher differences than those suggested by the computer results. Each protocol was run on $n=4$ samples. The infusion took around $1 \mathrm{~min}$ and was distributed at three points spaced $1 \mathrm{~cm}$ apart ( $20 \mathrm{~s}$ each) located along the electrode length and at the same depth as the electrode. This was done to achieve a more or less homogeneous distribution of the dopant around the electrode (see Fig. 7) and was similar to the method used in [28]. RFA started immediately after infusion.

After completing each RFA, the ablation site in the tissue was identified by carefully cutting along the active electrode's insertion path. The coagulation zone was defined de visu as the discolored white zone and images were taken with a digital camera. The axial and transverse diameters were measured by ImageJ software (National Institutes of Health, USA).

Acknowledgements

The authors wish to express their gratitude to the Polymer laboratory, under José Elías Pérez López PhD of the Physics Institute (UASLP), and CEECM LAB under Víctor Manuel Cárdenas Galindo PhD of the Engineering School (UASLP) for the material and equipment provided to carry out this research.

\section{Authors' contributions}

EB contributed with the planning of experiments and numerical models performed in this work. RR-M supervised the experimental work on the electrical properties of doped tissues and ex vivo experiments, and also contributed to building numerical models. DLC-L is the graduate student who built and performed the numerical simulations and experiments, and also helped to analyze the results obtained. All contributed equally to this work. All authors read and approved the final manuscript.

\section{Funding}

This work was supported by the National Council of Science and Technology (CONACYT, México) through a scholarship grant to Dora Luz Castro-López, CVU Registration No. 446604; and by the Spanish Ministerio de Ciencia, Innovación y Universidades under the "Plan Estatal de Investigación, Desarrollo e Innovación Orientada a los Retos de la Sociedad", Grant No "RTI2018-094357-B-C21".

\section{Availability of data and materials}

All the data generated or analyzed during this study are included in this published article.

Ethics approval and consent to participate

This article does not contain any studies with human participants or animals performed by any of the authors.

Consent for publication

Consent for publication was obtained for every individual person's data included in the study.

\section{Competing interests}

The authors declare that they have no competing interests.

\section{Author details}

${ }^{1}$ Facultad de Ingeniería, Universidad Autónoma de San Luis Potosí, San Luis Potosí SLP 78290, México. ${ }^{2}$ BioMIT, Department of Electronic Engineering, Universitat Politècnica de València, 46018 Valencia, Spain.

Received: 16 July 2020 Accepted: 15 December 2020

Published online: 06 January 2021

\section{References}

1. Zhu F, Rhim H. Thermal ablation for hepatocellular carcinoma: what's new in 2019. Chin Clin Oncol. 2019;8(6):58. https://doi.org/10.21037/cco.2019.11.03.

2. Haemmerich D. Biophysics of radiofrequency ablation. Crit Rev Biomed Eng. 2010;38(1):53-63. https://doi. org/10.1615/critrevbiomedeng.v38.i1.50 (PMID: 21175403).

3. Haines DE. Letter by Haines regarding article, "Direct measurement of the lethal isotherm for radiofrequency ablation of myocardial tissue." Circ Arrhythm Electrophysiol. 2011;4(5):e67. https://doi.org/10.1161/CIRCEP.111.965459 (author reply e68)

4. Ahmed M, Solbiati L, Brace CL, Breen DJ, Callstrom MR, Charboneau JW, Chen MH, Choi BI, de Baère T, Dodd GD 3rd, Dupuy DE, Gervais DA, Gianfelice D, Gillams AR, Lee FT Jr, Leen E, Lencioni R, Littrup PJ, Livraghi T, Lu DS, McGahan JP, Meloni MF, Nikolic B, Pereira PL, Liang P, Rhim H, Rose SC, Salem R, Sofocleous CT, Solomon SB, Soulen MC, Tanaka M, 
Vog I TJ, Wood BJ, Goldberg SN, International Working Group on Image-guided Tumor Ablation, Technology Assessment Committee of the Society of Interventional Radiology, Standard of Practice Committee of the Cardiovascular and Interventional Radiological Society of Europe. Image-guided tumor ablation: standardization of terminology and reporting criteria-a 10-year update. Radiology. 2014;273(1):241-60. https://doi.org/10.1148/radiol.14132958.

5. Trujillo M, Alba J, Berjano E. Relationship between roll-off occurrence and spatial distribution of dehydrated tissue during RF ablation with cooled electrodes. Int J Hyperthermia. 2012;28(1):62-8.

6. Jiang XY, Zhang TQ, Li G, Gu YK, Gao F, Yao W, Zhang YY, Huang JH. Increasing radiofrequency ablation volumes with the use of internally cooled electrodes and injected hydrochloric acid in ex vivo bovine livers. Int $J$ Hyperthermia. 2018;35(1):37-43.

7. Bruners P, Müller H, Günther RW, Schmitz-Rode T, Mahnken AH. Fluid-modulated bipolar radiofrequency ablation: an ex-vivo evaluation study. Acta Radiol. 2008;49(3):258-66.

8. Ishikawa T, Kubota T, Horigome R, Kimura N, Honda H, Iwanaga A, Seki K, Honma T, Yoshida T. Radiofrequency ablation during continuous saline infusion can extend ablation margins. World J Gastroenterol. 2013;19(8):1278-82. https://doi.org/10.3748/wjg.v19.18.1278.

9. Bennett D. NaCl doping and the conductivity of agar phantoms. Mater Sci Eng, C. 2011;31:494-8.

10. da Fonseca RD, Monteiro MS, Marques MP, Motta BC, Guimaraes GDA, do Santos PR, Jacobi RP, Rosa SSRF. Roll-off displacement in ex vivo experiments of RF ablation with refrigerated saline solution and refrigerated deionized water. IEEE Trans Biomed Eng. 2019:66(5):1390-401. https://doi.org/10.1109/TBME.2018.2873141.

11. Trujillo M, Berjano E. Review of the mathematical functions used to model the temperature dependence of electrical and thermal conductivities of biological tissue in radiofrequency ablation. Int J Hyperthermia. 2013;29(6):590-7.

12. Qadri AM, Chia NJY, Ooi EH. Effects of saline volume on lesion formation during saline-infused radiofrequency ablation. Appl Math Model. 2017:43:360-71.

13. Cherukuri P, Glazer ES, Curley SA. Targeted hyperthermia using metal nanoparticles. Adv Drug Deliv Rev. 2010;62(3):339-45.

14. Glazer ES, Curley SA. Non-invasive radiofrequency ablation of malignancies mediated by quantum dots, gold nanoparticles and carbon nanotubes. Ther Deliv. 2011;2(10):1325-30. https://doi.org/10.4155/tde.11.102.

15. Merkle EM, Goldberg SN, Boll DT, Shankaranarayanan A, Boaz T, Jacobs GH, Wendt M, Lewin JS. Effects of superparamagnetic iron oxide on radio-frequency-induced temperature distribution: in vitro measurements in polyacrylamide phantoms and in vivo results in a rabbit liver model. Radiology. 1999;212(2):459-66. https://doi.org/10.1148/ radiology.212.2.r99au44459.

16. Pedro RN, Thekke-Adiyat T, Goel R, Shenoi M, Slaton J, Schmechel S, Bischof J, Anderson JK. Use of tumor necrosis factor-alpha-coated gold nanoparticles to enhance radiofrequency ablation in a translational model of renal tumors. Urology. 2010;76(2):494-8. https://doi.org/10.1016/j.urology.2010.01.085.

17. Wu Q, Zhang H, Chen M, Zhang Y, Huang J, Xu Z, Wang W. Preparation of carbon-coated iron nanofluid and its application in radiofrequency ablation. J Biomed Mater Res B Appl Biomater. 2015;103(4):908-14. https://doi. org/10.1002/jbm.b.33275.

18. Jelbuldina M, Korganbayev S, Korobeinyk AV, Inglezakis VJ, Tosi D. Temperature profiling of ex-vivo organs during ferromagnetic nanoparticles-enhanced radiofrequency ablation by Fiber Bragg Grating Arrays. Annu Int Conf IEEE Eng Med Biol Soc. 2018;2018:1-4. https://doi.org/10.1109/EMBC.2018.8513227.

19. Khalafalla MAH, Mesli A, Widattallah HM, Sellai A, Al-harthi S, Al-Lawati HAJ, Suliman FO. Size-dependent conductivity dispersion of gold nanoparticle colloids in a microchip: contactless measurements. J Nanoparticle Res. 2014;16:2546.

20. Ewertowska E, Quesada R, Radosevic A, Andaluz A, Moll X, Arnas FG, Berjano E, Burdío F, Trujillo M. A clinically oriented computer model for radiofrequency ablation of hepatic tissue with internally cooled wet electrode. Int Hyperthermia. 2019;35(1):194-204

21. Raoof M, Corr SJ, Zhu C, Cisneros BT, Kaluarachchi WD, Phounsavath S, Wilson L, Curley SA. Gold nanoparticles and radiofrequency in experimental models for hepatocellular carcinoma. Nanomedicine. 2014;10(6):1121-30.

22. Xie H, Wang J, Xi T, Liu Y. Thermal conductivity of suspensions containing nanosized SiC particles. Int J Thermophys. 2002;23:571-80

23. Yull Park J, Young Park C, Min Lee J. Estimation of saline-mixed tissue conductivity and ablation lesion size. Comput Biol Med. 2013:43(5):504-12

24. Abdelhalim MAK, Mady MM, Ghannam MM. Dielectric constant, electrical conductivity and relaxation time measurements of different gold nanoparticle sizes. Int J Phys Sci. 2011;6(23):5487-91.

25. Zorbas G, Samaras T. Parametric study of radiofrequency ablation in the clinical practice with the use of two-compartment numerical models. Electromagn Biol Med. 2013;32(2):236-43.

26. Zhang B, Moser MA, Zhang EM, Luo Y, Zhang H, Zhang W. Study of the relationship between the target tissue necrosis volume and the target tissue size in liver tumours using two-compartment finite element RFA modelling. Int J Hyperthermia. 2014;30(8):593-602.

27. Francica G. Needle track seeding after radiofrequency ablation for hepatocellular carcinoma: prevalence, impact, and management challenge. J Hepatocell Carcinoma. 2017;20(4):23-7.

28. Ji Q, Xu Z, Liu G, Lin M, Kuang M, Lu M. Preinjected fluids do not benefit microwave ablation as those in radiofrequency ablation. Acad Radiol. 2011;18(9):1151-8.

29. Goldberg SN, Stein MC, Gazelle GS, Sheiman RG, Kruskal JB, Clouse ME. Percutaneous radiofrequency tissue ablation: optimization of pulsed-radiofrequency technique to increase coagulation necrosis. J Vasc Interv Radiol. 1999;10(7):907-16.

30. Solazzo SA, Ahmed M, Liu Z, Hines-Peralta AU, Goldberg SN. High-power generator for radiofrequency ablation: larger electrodes and pulsing algorithms in bovine ex vivo and porcine in vivo settings. Radiology. 2007:242(3):743-50

31. Goldberg SN, Ahmed M, Gazelle GS, Kruskal JB, Huertas JC, Halpern EF, Oliver BS, Lenkinski RE. Radio-frequency thermal ablation with $\mathrm{NaCl}$ solution injection: effect of electrical conductivity on tissue heating and coagulationphantom and porcine liver study. Radiology. 2001;219(1):157-65. 
32. Trujillo M, Bon J, Berjano E. Computational modelling of internally cooled wet (ICW) electrodes for radiofrequency ablation: impact of rehydration, thermal convection and electrical conductivity. Int J Hyperthermia. 2017;33(6):624-34.

33. Gillams AR, Lees WR. CT mapping of the distribution of saline during radiofrequency ablation with perfusion electrodes. Cardiovasc Intervent Radiol. 2005;28(4):476-80.

34. Takata AN, Zaneveld L, Richter W. Laser-induced thermal damage of skin (Rep. SAM-TR-77-38). USAF School Aerospace Medicine, Brooks Air Force Base, Texas. 1977: 22-3.

35. Burdío F, Berjano E, Millan O, Grande L, Poves I, Silva C, de la Fuente MD, Mojal S. CT mapping of saline distribution after infusion of saline into the liver in an ex vivo animal model. How much tissue is actually infused in an imageguided procedure? Phys Med. 2013;29(2):188-95.

36. Abraham JP, Sparrow EM. A thermal-ablation bioheat model including liquid-to-vapor phase change, pressure- and necrosis-dependent perfusion, and moisture-dependent properties. Int J Heat Mass Transfer. 2007;50:2537-44.

37. Pätz T, Kröger T, Preusser T, Simulation of radiofrequency ablation including water evaporation, IFMBE Proceedings, 25/IV:1287-90, 2009.

38. https://www.engineeringtoolbox.com/specific-heat-capacity-water-d_660.html (accessed March 15, 2020).

39. Carson JK. Review of effective thermal conductivity models for foods. Int J Refrigeration. 2006;29(6):958-67.

40. Cruz RCD, Reinshagen J, Oberacker R, Segadães AM. Electrical conductivity and stability of concentrated aqueous alumina suspensions. J Colloid Interface Sci. 2005;286:579-88.

41. Trujillo M, Bon J, Rivera MJ, Burdio F, Berjano E. Computer modelling of an impedance-controlled pulsing protocol for RF tumour ablation with a cooled electrode. Int J Hyperthermia. 2016;32:931-9.

\section{Publisher's Note}

Springer Nature remains neutral with regard to jurisdictional claims in published maps and institutional affiliations.

- fast, convenient online submission

- thorough peer review by experienced researchers in your field

- rapid publication on acceptance

- support for research data, including large and complex data types

- gold Open Access which fosters wider collaboration and increased citations

- maximum visibility for your research: over 100M website views per year

At BMC, research is always in progress.

Learn more biomedcentral.com/submissions 